\title{
Long-term monthly statistics of the mid-latitude ionospheric E-layer peak electron density in the Northern geographic hemisphere during geomagnetically quiet and steadily low solar activity conditions
}

\author{
Anatoli V. Pavlov ${ }^{1, \star}$, Nadezhda M. Pavlova ${ }^{1}$ \\ ${ }^{1}$ Pushkov Institute of Terrestrial Magnetism, Ionosphere and Radio-Wave Propagation of the Russian Academy of Sciences \\ (IZMIRAN), Moscow, Troitsk, Russia
}

Article history

Received January 21, 2016; accepted February 20, 2017.

Subject classification:

Mid-latitude ionosphere, E-region, Modeling and forecasting.

\begin{abstract}
Long-term hourly values of the ionospheric E-layer peak electron density, NmE, measured from 1957 to 2014 by 4 mid-latitude ionosondes (Wallops Island, Boulder, de l'Ebre, and Rome) in the Northern geographic hemisphere were processed to select periods of geomagnetically quiet and low solar activity conditions using the 3-hour index, Ap, of geomagnetic activity and the daily solar $10.7 \mathrm{~cm}$ radio flux index, F10.7, of solar activity. The selected ionospheric E-layer peak electron densities are used to calculate several descriptive statistics of $\mathrm{NmE}$ close to noon for each month in a year, including the mathematical expectation of NmE, the standard deviation of NmE from the mathematically expected NmE, and the coefficient of variations of $N m E$. The month-to-month variability of these descriptors allowed us to identify months when they reach their extremes (maxima, minima).
\end{abstract}

\section{Introduction}

Production and loss processes of ions and electrons of the mid-latitude ionospheric E-region are well studied [see, e.g., Schunk and Nagy, 2009; Pavlov, 2012, Pavlov and Pavlova, 2013, 2015, and references therein]. Analyzing production and loss rates of ions and electrons of the ionospheric E-region, it is possible to establish causes of day-to-day variations of the mid-latitude E-region peak electron density, NmE, during each month of a year under given local time, latitude, and longitude. The major sources of this variability of NmE are changes of X-ray and EUV solar irradiance with solar activity, variations of number densities and temperature of neutral species with solar and geomagnetic activity, and changes of the solar zenith angle [e.g., Moore et al., 2006, Pavlov and Pavlova, 2013, 2015].

Day-to-day variability of ionospheric E-region electron densities remains a topic of interest [see, e.g., Kouris and Fotiadis, 2002; Moore et al., 2006; Ni- colls et al., 2012, and references therein]. The hourly values of the critical frequency, foE (which is proportional to the square root of $\mathrm{NmE}$ [Piggot and Raver, 1978]), of the ionospheric E-layer measured by 30 mid-latitude ionosondes during the period of 1964-1995 were used by Kouris and Fotiadis [2002] to evaluate day-to-day variability of foE. They found that positive and negative relative deviations of foE from the monthly median values of foE are within the range of $10 \%$ for more than $90 \%$ of the time. Noontime day-to-day ionosonde and incoherent scatter radar measurements of the $\mathrm{E}$ layer parameters were used by Moore et al. [2006] to calculate the standard relative deviations of $\mathrm{NmE}$ from noontime $\mathrm{NmE}$ mean values in the range of $5-7 \%$ at middle latitudes for 9-27 March 1999 and 4 October - 4 November 2002. Slightly larger values of $\mathrm{NmE}$ variability were estimated by Nicolls et al. [2012] using the inversion technique from satellite-based radio occultation total electron content measurements. However, little attention has been given in these and other published morphological studies to $\mathrm{NmE}$ data sorting due to apparent variability of solar and geomagnetic activity. Thus, this published $\mathrm{NmE}$ statistics in fact describes a mix of day-to-day variations of geomagnetically quiet $\mathrm{NmE}$ at a steady solar activity and variations of $\mathrm{NmE}$ in response to changing geomagnetic and solar activity conditions.

The daily solar $10.7 \mathrm{~cm}$ radio flux index, F10.7, (or a daily sunspot number) and the 3-hour geomagnetic index, Ap (or Kp), are the most widely used indices for exploring causes and consequences of solar and geomagnetic activity [see, e.g., Akasofu and Chapman, 1972; Schunk and Nagy, 2009]. Therefore, the F10.7 and 
Ap indices are used in our work to describe dependencies of NmE on solar and geomagnetic activities, respectively.

$\mathrm{NO}^{+}$and $\mathrm{O}_{2}{ }^{+}$ions are the main ions at the E-region altitudes of the ionosphere, and the characteristic time to approach the photochemical equilibrium by dissociative recombination reactions of these ions with electrons is less than one minute during daytime conditions close to the E-layer peak altitude [Banks and Kockarts, 1973]. The value of this characteristic time is much less than 3 hours. As a result, variations of $\mathrm{NmE}$ caused by changes in geomagnetic activity during a period that is less than 3 hours are not described in terms of changes of Ap and can be considered as random variations of $\mathrm{NmE}$ if the Ap index is used to study a dependence of $\mathrm{NmE}$ on geomagnetic activity.

The sun is not static throughout each day, and changing X-ray and EUV irradiance with time periods less than 24 hours are not captured by the F10.7 index of solar activity or by any other daily index of solar activity [Acebal and Sojka, 2011]. Hence, if the solar ionizing fluxes are changing significantly during a few hours due to flares and also an overall background change, the daytime NmE will respond, but this response of $\mathrm{NmE}$ cannot be described in terms of variations of F10.7. It should be also noted that the integral solar flux below $200 \mathrm{~nm}$ increases with a rise in the average index $0.5(\mathrm{~F} 10.7+\overline{\mathrm{F} 10.7})$ only on average, and there are significant deviations from the linear correlation between this integral solar flux and this average index where $\overline{\mathrm{F} 10.7}$ is the 81-day average of daily F10.7 solar activity indices centered on the day under study [Solomon, 2006]. Manson [1976] has also pointed out that the correlation of the integrated solar flux between $5.2 \mathrm{~nm}$ and $12 \mathrm{~nm}$ with $\mathrm{F} 10.7$ is poor.

On the other hand, there is significant influence of variations in X-ray irradiance on $\mathrm{NmE}$ [Pavlov and Pavlova, 2013, 2015, Sojka et al., 2014]. From the above reasoning, differences between $\mathrm{NmE}$ calculated by the one-dimensional time-dependent theoretical mid-latitude model of the E-region ion composition and $\mathrm{NmE}$ measured by the Boulder and Moscow ionosondes can be explained by uncertainties up to a factor of 2 in predictions of X-ray radiation on the basis of changes in the F10.7 and $\overline{\mathrm{F} 10.7}$ indices [Pavlov and Pavlova, 2013, 2015]. As a result, the use of the F10.7 index as an indicator of solar activity in statistical studies of $\mathrm{NmE}$ can be one of sources of deviations of $\mathrm{NmE}$ from the expected $\mathrm{NmE}$ for the chosen level of solar activity, and these deviations caused by the use of the F10.7 index can be considered as random variations of $\mathrm{NmE}$.
The quiet time ionospheric E-layer number densities measured by an ionosonde during a month depend on the solar zenith angle which value is changed during this month. However, the existence of a day in a month at low solar activity does not mean that all days in this month correspond to the low solar activity conditions under consideration. In addition to that, geomagnetically quiet time periods are randomly distributed during each month of a year. Thus, day-today variability of $\mathrm{NmE}$ at given local time during each month of a year caused by changes of the solar zenith angle is modified in a random way due to variations of solar and geomagnetic activity.

The foregoing shows that the daytime value of NmE measured by an ionosonde during geomagnetically quiet conditions at low solar activity under given local time during a month in a year can be considered as a random variable. The objective of this work is to apply the mathematical statistics, as described, for example, by Johnson and Leone [1977], to study this variability of $\mathrm{NmE}$ using $\mathrm{NmE}$ measured by the mid-latitude ionosondes at Wallops Island, Boulder, de l'Ebre, and Rome in the Northern geographic hemisphere from 1957 to 2014 during geomagnetically quiet conditions at low solar activity. For achievement of this purpose, we calculate the mathematically expected, $<\mathrm{NmE}>$, and most probable, $\mathrm{NmE}_{\mathrm{MP}}$, values of $\mathrm{NmE}$, the standard deviations of $\mathrm{NmE}$ from $<\mathrm{NmE}>$ and $\mathrm{NmE}_{\mathrm{MP}}$, and the coefficients of variations of $\mathrm{NmE}$ relative to $<\mathrm{NmE}>$ and $\mathrm{NmE}_{\mathrm{MP}}$ for each month of a year using data collected by 4 mid-latitude ionosondes in the Northern geographic hemisphere. As a result, month-to-month variations of the above listed statistical parameters of $\mathrm{NmE}$ over each ionosonde are studied.

\section{Data and Method of Data Analysis}

The ionosonde data for this investigation were obtained from the NOAA National Geophysical Data Center (NGDC) in Boulder, Colorado, using its online Space Physics Interactive Data Resource (SPIDR). First, we selected the hourly values of foE observed in 1957-2014 by 4 ionosondes (Wallops Island, Boulder, de l'Ebre, and Rome) in the Northern geographic hemisphere. Table 1 provides the geographic latitude and longitude $(\phi, \lambda)$, and average geomagnetic latitude and longitude $(\Phi, \Lambda)$ of each ionosonde. The ionosonde stations presented in Table 1 are listed in order of increasing geographic latitude. It follows from the calculations [details are described by Pavlov and Pavlo$v a, 2014]$ that the geomagnetic coordinates of the ionosondes under consideration averaged over the time 
period from 1957 to 2012 and given by Pavlov and Pavlo$v a[2014]$ are practically the same as for the time period of 1957-2014, and these average values of $\Phi$ and $\Lambda$ are presented in Table 1. We believe that, under quiet geomagnetic conditions, the mid-latitude ionosphere is located between $30^{\circ}$ and $55^{\circ}$ geomagnetic latitudes in the Northern geographic hemisphere. The stations used are all located within the $30^{\circ}$ to $55^{\circ}$ geomagnetic latitude interval, representing the mid-latitude ionosphere.

$\mathrm{NmE}$ values were obtained from foE using their well known relationship [e.g., Piggott and Rawer, 1978]

$$
\mathrm{NmE}=1.24 \cdot 10^{4} \mathrm{foE}^{2},
$$

where the units of $\mathrm{NmE}$ and foE are $\mathrm{cm}^{-3}$ and $\mathrm{MHz}$, respectively.

The hourly foE records acquired from the NGDC archives were analyzed to select values corresponding to time points during the geomagnetically quiet periods defined below with UT closest to the solar noon in the solar local time, SLT (see Table 1). The relationship between UT and SLT is defined by UT $=$ SLT $-\lambda / 15$, where $\lambda$ is the East geographic longitude of the ionospheric observatory in degrees, while SLT and UT come in units of hours. It should be noted that the values of foE measured by the Juliusruh ionosonde at 10:58 UT are provided by the NGDC archives for the time period from 26 March 2007 to 31 December 2014, and these measurements are used in our statistical study in place of missing Juliusruh ionosonde measurements of foE at 11:00 UT for this time period (see Table 1).

The E-region ion and electron densities depend on geomagnetic activity due to variations of the neutral temperature and densities with geomagne- tic activity. These changes in the neutral temperature and densities can be described by variations of 7 indices: the daily Ap index, the 3-hour Ap index for current time, the 3-hour Ap indices for 3, 6, and 9 hours before current time, the average of eight 3-hour Ap indices from 12 to 33 hours prior to current time, and the average of eight 3-hour Ap indices from 36 to 57 hours prior to current time [Hedin, 1987; Picone et al., 2002]. The relationship between indices Ap and $\mathrm{Kp}$ is well established, and the value of $\mathrm{Ap}=18$ corresponds to $\mathrm{Kp}=3$ [Akasofu and Chapman, 1972]. The geomagnetically quiet conditions for the candidate noon foE values were identified by ensuring that each of the seven above-mentioned indices of geomagnetic activity was equal to 18 or was less than 18. To select periods of steadily low solar activity, we relied on analysis of three indices derived from observations of F10.7. The solar EUV flux, primarily responsible for the daytime ionization, is approximately represented by F10.7 and $\overline{\mathrm{F} 10.7}[R i$ chards et al., 1994]. The electron density also depends on the solar-controlled neutral temperature and densities whose dependences on F10.7p (F10.7 for a day preceding a day under consideration) and $\overline{\text { F10.7 }}$ are well established [Hedin, 1987; Picone et al., 2002]. All three indices, F10.7, F10.7p, and $\overline{\mathrm{F} 10.7}$, were used to control selection of the foE data by retaining only those days for which these indices were within the 65 to 85 interval (in $10^{-22} \mathrm{~W} \cdot \mathrm{m}^{-2} \cdot \mathrm{Hz}^{-1}$ ).

We consider sets of foE(UT,M) and $\mathrm{NmE}(\mathrm{UT}, \mathrm{M})$ for each month, $\mathrm{M}$, in a year at the given UT for each location. The results of measurements of foE are presented in the database with the step, $\Delta \mathrm{foE}$, of $0.05 \mathrm{MHz}$, i.e. the considered foE are given on the

\begin{tabular}{|c|c|c|c|c|c|c|c|}
\hline Ionosonde & $\begin{array}{c}\phi \\
\left(^{\circ}\right)\end{array}$ & $\begin{array}{c}\lambda \\
\left(^{\circ}\right)\end{array}$ & $\begin{array}{c}\Phi \\
\left(^{\circ}\right)\end{array}$ & $\begin{array}{c}\Lambda \\
\left(^{\circ}\right)\end{array}$ & Years & UT & SLT \\
\hline Wallops Island & 37.8 & 284.5 & 45.3 & 358.6 & $1967-2014$ & 17:00 & $11: 58$ \\
\hline \multirow[t]{2}{*}{ Boulder } & 40.0 & 254.7 & 46.9 & 325.2 & 1958-1960, 1962-2002, & 19:00 & $11: 59$ \\
\hline & & & & & 2004-2014 & & \\
\hline \multirow[t]{3}{*}{ De l'Ebre } & 40.8 & 0.3 & 40.8 & 76.7 & 1957-1980, 1982-1987, & $12: 00$ & 12:01 \\
\hline & & & & & 1991-1995, 1998-2004, & & \\
\hline & & & & & 2007-2014 & & \\
\hline Rome & 41.8 & 12.5 & 40.0 & 88.4 & $1976-2004,2007-2014$ & 11:00 & $11: 50$ \\
\hline
\end{tabular}

Table 1. The ionosonde names and locations, and time ranges of foE measurements at the universal time, UT, closest to the solar noon in the solar local time, SLT. 
uniform grid of foE $_{\mathrm{k}}=\mathrm{k} \Delta$ foE, where $\mathrm{k}=1,2, \ldots \mathrm{K}$, and $\mathrm{K}$ is the maximal value of $\mathrm{k}$. The measured critical frequencies fo $E_{k}$ and Eq. (1) allow to determine the corresponding measured E-layer peak electron densities $\mathrm{NmE}_{\mathrm{k}}$ at the corresponding non-uniform grid of $\mathrm{NmE}_{\mathrm{k}}$.

The probability, $\mathrm{P}_{\mathrm{k}}(\mathrm{UT}, \mathrm{M})$, to measure a geomagnetically quiet $\mathrm{NmE}_{\mathrm{k}}(\mathrm{UT}, \mathrm{M})$ is counted individually for each ionosonde, UT, and $\mathrm{M}$ as

$$
P_{k}(U T, M)=F_{k}(U T, M) / F(U T, M),
$$

where $\mathrm{F}_{\mathrm{k}}(\mathrm{UT}, \mathrm{M})$ is a number of $\mathrm{NmE}_{\mathrm{k}}(\mathrm{UT}, \mathrm{M})$, $\mathrm{F}(\mathrm{UT}, \mathrm{M})=\sum_{\mathrm{K}}^{K} \mathrm{~F}_{\mathrm{k}}(\mathrm{UT}, \mathrm{M})$ is the total number of selected $\mathrm{NmE}_{\mathrm{k}}(\mathrm{UT}, \mathrm{M})$ values.

It follows from Eq. (2) that $\sum_{k=1}^{K} P_{k}(U T, M)=1$.

It should be noted that the value of F(UT,M) turned out to be at least 101 or greater than 101 for each ionosonde. We believe that this value of $F(U T, M)$ is enough large to carry out our statistical study.

We define the mathematical expectation of $\mathrm{NmE}$ to be

$$
<N m E(U T, M)>=\sum_{k=1}^{K} P_{k}(U T, M) N m E_{k}
$$

The standard deviation of $\mathrm{NmE}$ from $<\mathrm{NmE}>$ is calculated as

$$
\sigma_{A V}(U T, M)=\left\{\sum_{k=1}^{K} P_{k}(U T, M)\left[N m E_{k}-<N m E(U T, M)>\right]^{2}\right\}^{0.5} \cdot \text { (4) }
$$

The coefficient of variations of $\mathrm{NmE}$ relative to $<\mathrm{NmE}>$ (the relative standard deviation of $\mathrm{NmE}$ from $<\mathrm{NmE}>$ ) expressed as a percentage takes a form

$$
C V_{A V}(U T, M)=100 \sigma_{A V}(U T, M) /<N m E(U T, M)>.
$$

All values of $\mathrm{NmE}_{\mathrm{k}}$ are not equally probable, and $\mathrm{P}_{\mathrm{k}}$ reaches its maximum at the most probable value, $\mathrm{NmE}_{\mathrm{MP}}$, of $\mathrm{NmE}$. The standard deviation, $\sigma_{\mathrm{MP}}$, of $\mathrm{NmE}$ from $\mathrm{NmE}_{\mathrm{MP}}$ and the coefficient, $\mathrm{CV}_{\mathrm{MP}}$, of variations of $\mathrm{NmE}$ relative to $\mathrm{NmE}_{\mathrm{MP}}$ (the relative standard deviation of $\mathrm{NmE}$ from $\mathrm{NmE}_{\mathrm{MP}}$ ) are calculated as

$$
\begin{gathered}
\sigma_{M P},(U T, M)=\left[\sum_{k=1}^{K} P_{k}(U T, M)\left(N m E_{k}-N m E_{M P}\right)^{2}\right]^{0.5} . \\
C V_{M P}(U T, M)=100 \sigma_{M P}(U T, M) / N m E_{M P}
\end{gathered}
$$

\section{Results and Discussion}

The use of the statistical approach to study month-to-month variations in the statistical parameters of $\mathrm{NmE}$ is motivated by a variability of NmE during geomagnetically quiet conditions for approximately the same solar activity at the same UT and location during each month. If these conditions are carried out then day-to-day variability of $\mathrm{NmE}$ determines a dependence of $\mathrm{P}_{\mathrm{k}}(\mathrm{UT}, \mathrm{M})$ on $\mathrm{NmE}_{\mathrm{k}}$. Examples of this dependence are shown in Figure 1 when the Boulder ionosonde data at 19:00 UT (11:59 SLT) are used in the statistical study. Circles and pluses in Figure 1 correspond to January and February (left top panel), March and April (left middle panel), May and June (left bottom panel), July and August (right top panel), September and October (right middle panel), and November and December (right bottom panel), respectively.

It follows from the calculations that each dependence of $\mathrm{P}_{\mathrm{k}}\left(\mathrm{UT}, \mathrm{M}\right.$ ) on $\mathrm{NmE}_{\mathrm{k}}$ (see Figure 1) is a sequence of peaks in $\mathrm{P}_{\mathrm{k}}(\mathrm{UT}, \mathrm{M})$, and a location of the largest peak in the $\mathrm{NmE}_{\mathrm{k}}$-axes determines the most probable, $\mathrm{NmE}_{\mathrm{MP}}$, value of $\mathrm{NmE}$ for each month under consideration. Figure 1 shows that, with the exception of the March dependence of $\mathrm{P}_{\mathrm{k}}(\mathrm{UT}, \mathrm{M})$ on $\mathrm{NmE}_{\mathrm{k}}$, each of the dependences of $\mathrm{P}_{\mathrm{k}}(\mathrm{UT}, \mathrm{M})$ on $\mathrm{NmE}_{\mathrm{k}}$ has a peak in $\mathrm{P}_{\mathrm{k}}(\mathrm{UT}, \mathrm{M})$ whose amplitude is not much less than that of the largest peak in $\mathrm{P}_{\mathrm{k}}(\mathrm{UT}, \mathrm{M})$ for this dependence. It should be noted that the mathematical expectation of NmE defined by Eq. (3) takes into account the relative contribution of each value of $\mathrm{NmE}_{\mathrm{k}}$ in accordance with the value of $\mathrm{P}_{\mathrm{k}}(\mathrm{UT}, \mathrm{M})$ for this $\mathrm{NmE}_{\mathrm{k}}$, and all significant peaks in each dependence of $\mathrm{P}_{\mathrm{k}}(\mathrm{UT}, \mathrm{M})$ on $\mathrm{NmE}_{\mathrm{k}}$ under consideration are taking into account in $<\mathrm{NmE}>$.

Figures 2-4 show month-to-month variations in the calculated values of $<\mathrm{NmE}>$ (crosses in Figure 2), $\mathrm{NmE}_{\mathrm{MP}}$ (squares in Figure 2), $\sigma_{\mathrm{AV}}$ (crosses in Figure $3), \sigma_{\mathrm{MP}}$ (squares in Figure 3), $\mathrm{CV}_{\mathrm{MP}}$ (crosses in Figure 4), and $\mathrm{CV}_{\mathrm{MP}}$ (squares in Figure 4) over the Wallops Island (left top panels), Boulder (left bottom panels), de l'Ebre (right top panels), and Rome (right bottom panels) ionosondes. It follows from our calculations that each statistical parameter of $\mathrm{NmE}$ is changed from ionosonde to ionosonde for the same month due to differences in geographic latitudes and longitudes of the ionosondes and in the values of SLT when these measurements were carried out by the ionosondes (see Table 1).

Percent differences between $\mathrm{NmE}_{\mathrm{MP}}$ and $<\mathrm{NmE}>$ can be calculated for each month in a year as $200 \mid \mathrm{NmE}_{\mathrm{MP}}$ - $<\mathrm{NmE}>\mid /\left(\mathrm{NmE}_{\mathrm{MP}}+<\mathrm{NmE}>\right)$. This difference depends on $M$, and reaches its maximum value, $Z\left(\mathrm{NmE}_{\mathrm{M}-}\right.$ ${ }_{\mathrm{P}}<\mathrm{NmE}>$ ), that varies from an ionosonde to an ionosonde. We found that $Z\left(\mathrm{NmE}_{\mathrm{MP}}<\mathrm{NmE}>\right)=8.1,6.1,4.4$, and $4.5 \%$ for the Wallops Island, Boulder, de l'Ebre, and Rome ionosondes, respectively.

The calculated month-to-month variations of 


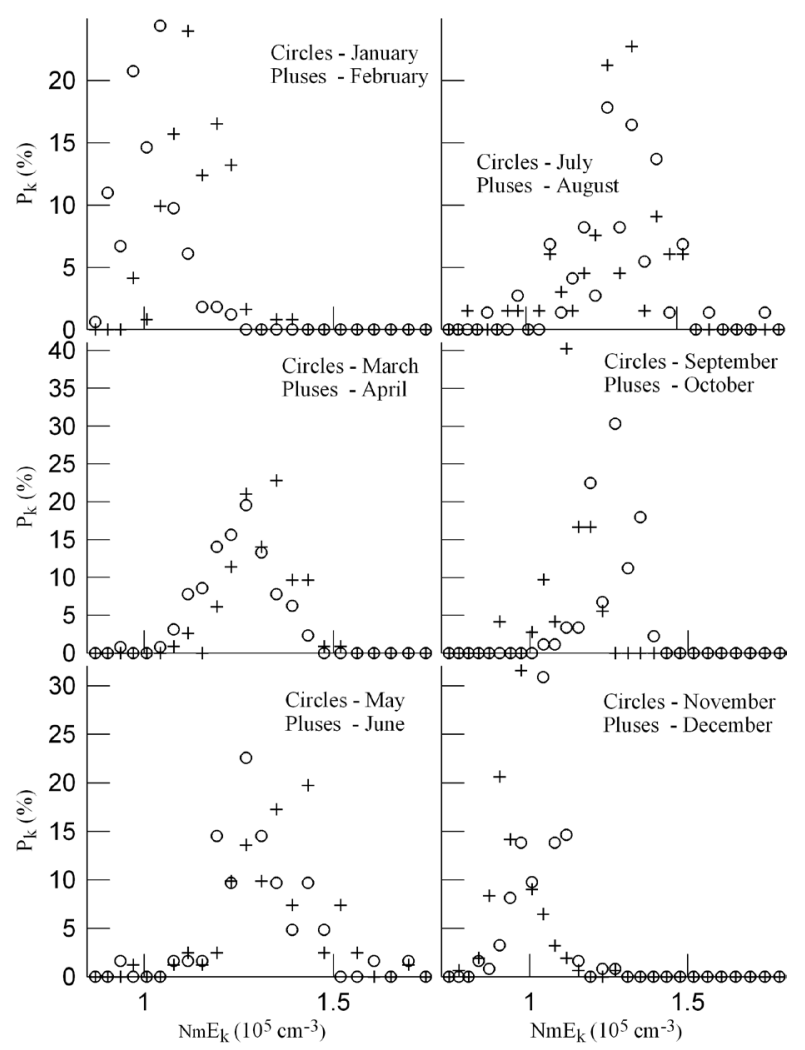

Figure 1. Dependencies of $\mathrm{P}_{k}(\mathrm{UT}, \mathrm{M})$ on $\mathrm{NmE}_{\mathrm{k}}$ over the Boulder ionosonde. Circles and pluses correspond to January and February (left top panel), March and April (left middle panel), May and June (left bottom panel), July and August (right top panel), September and October (right middle panel), and November and December (right bottom panel).

$<\mathrm{NmE}>$ and $\mathrm{NmE}_{\mathrm{MP}}$ shown in Figure 2 are both trying to estimate month-to-month variations of NmE. What is better?

It follows from the calculations of $\sigma_{\mathrm{AV}}$ and $\sigma_{\mathrm{MP}}$ presented in Figure 3 that

$$
\sigma_{A V}(U T, M)<\sigma_{M P}(U T, M)
$$

The standard deviations of $\mathrm{NmE}$ from $<\mathrm{NmE}>$ and $\mathrm{NmE}_{\mathrm{MP}}$ measure spreads of distributions of $\mathrm{NmE}$ about $<\mathrm{NmE}>$ and $\mathrm{NmE}_{\mathrm{MP}}$, respectively. We believe that, the smaller this spread, the more efficient the estimation. As a result, the calculated month-to-month variations of $<\mathrm{NmE}>$ presented in Figure 2 can be considered as the most efficient estimation of month-to-month variations of $\mathrm{NmE}$ for the ionosonde measurements under consideration.

The calculations show (see Figure 4) that, as a rule, $\mathrm{CV}_{\mathrm{AV}}(\mathrm{UT}, \mathrm{M})<\mathrm{CV}_{\mathrm{MP}}(\mathrm{UT}, \mathrm{M})$ with the exception of $M=2,6,7,10$, and 11 for the Rome, Delebre, Rome, Wallops Island, and Delebre ionosonde, respectively, and a difference between $\mathrm{CV}_{\mathrm{AV}}(\mathrm{UT}, \mathrm{M})$ and $\mathrm{CV}_{\mathrm{M} \text { - }}$ ${ }_{\mathrm{p}}(\mathrm{UT}, \mathrm{M})$ is negligible for each of these exceptions. Thus, the calculated month-to-month variations of
$<\mathrm{NmE}>$ can be considered as the most efficient estimation of month-to-month variations of $\mathrm{NmE}$ if we compare not only $\sigma_{\mathrm{AV}}(\mathrm{UT}, \mathrm{M})$ with $\sigma_{\mathrm{MP}}(\mathrm{UT}, \mathrm{M})$ but also $\mathrm{CV}_{\mathrm{AV}}(\mathrm{UT}, \mathrm{M})$ with $\mathrm{CV}_{\mathrm{MP}}(\mathrm{UT}, \mathrm{M})$. Based on this conclusion, the calculated month-to-month variations of $\mathrm{NmE}_{\mathrm{MP}}, \sigma_{\mathrm{MP}}$ and $\mathrm{CV}_{\mathrm{MP}}$ are not discussed further.

It follows from Figure 2 that the annual maximum of $<\mathrm{NmE}>$ is formed in May (Wallops Island and Rome), June (Boulder), and July (de l'Ebre). The mathematical expectation of $\mathrm{NmE}$ is lowest in its annual value in December. A ratio of the largest to lowest value of the mathematically expected $\mathrm{NmE}$ characterizes the maximal month-to-month variability of this statistical parameter of $\mathrm{NmE}$ in a year. This ratio is found to be $1.40,1.41,1.43$, and 1.43 for the Wallops Island, Boulder, de l'Ebre, and Rome ionosondes. We also point out that local minima of $<\mathrm{NmE}>$ are formed in May, June, and July over the Boulder, Rome, and Wallops Island ionosondes, respectively.

By analogy with the definition of the winter anomaly of the F2-layer peak electron density (see, e.g., Pavlov and Pavlova [2005, 2009], Pavlov et al. [2010], and references therein), the winter anomaly of $\mathrm{NmE}$ can be defined as follows. If the E-layer peak electron density is sometimes greater in winter than that in summer over the same Earth's surface point during geomagnetically quiet daytime conditions at the same universal time despite the reduced solar insolation in winter in comparison with that in summer then this ionospheric phenomenon can be designated as the winter anomaly of $\mathrm{NmE}$. It follows from Figure 2 that the winter anomaly of $\langle\mathrm{NmE}\rangle$ is not observed over the Wallops Island, Boulder, de l'Ebre, and Rome ionosondes.

It is seen from Figure 3 that the annual maximum of the standard deviation of $\mathrm{NmE}$ from $<\mathrm{NmE}>$ occurs in July over all ionosondes under consideration. The lowest annual value of $\sigma_{\mathrm{AV}}$ is found to be in January (de l'Ebre), February (Wallops Island), October (Boulder), and December (Rome).

Figure 4 shows that the coefficient of variations of NmE maximizes in its annual value in July. This coefficient minimizes in its annual value in January (de l'Ebre), February (Wallops Island), September (Boulder), and October (Rome). It follows from the comparison of $\mathrm{CV}_{\mathrm{AV}}$ of all 4 ionosondes that $\mathrm{CV}_{\mathrm{AV}}$ reaches its lowest and largest values in its month-to-month variations over the de l'Ebre and Wallops Island ionosondes, respectively. If all 4 ionoson- 


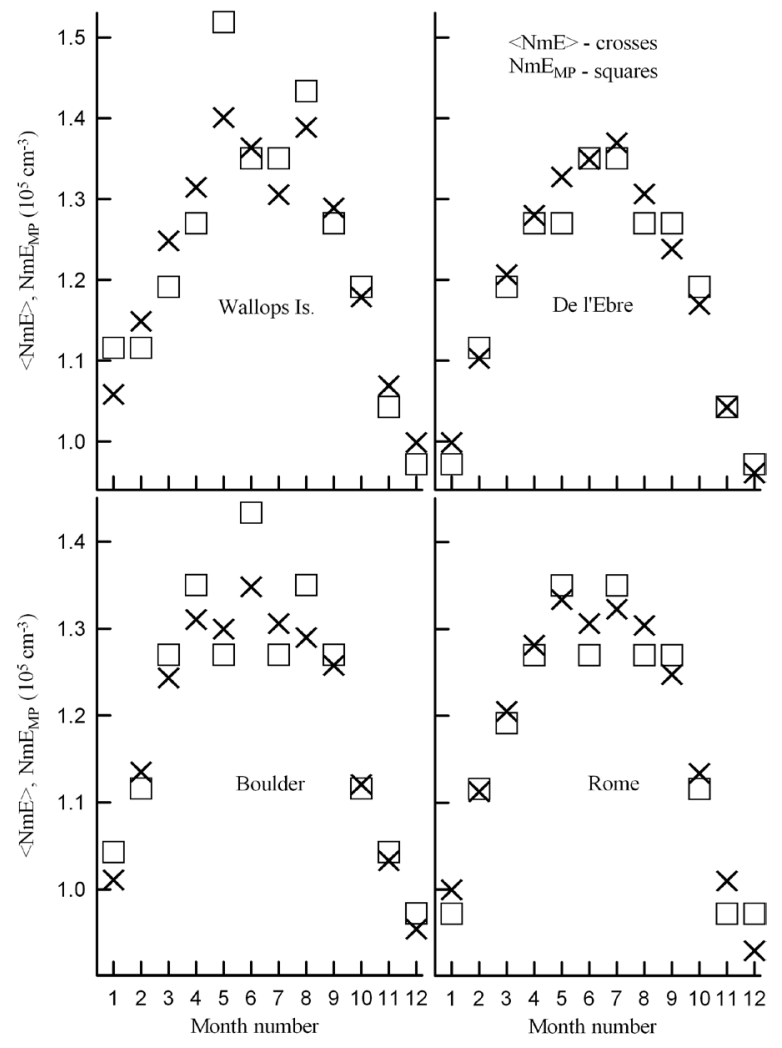

Figure 2. Month-to-month variations of the mathematically expected $\mathrm{NmE}$ (crosses) and the most probable $\mathrm{NmE}$ (squares) over the Wallops Island (left top panel), Boulder (left bottom panel), de l'Ebre (right top panel), and Rome (right bottom panel) ionosondes.

des are considered then the value of $\mathrm{CV}_{\mathrm{AV}}$ is located in the range of 5.1-11.9\%. We point out that the calculated coefficients of variations of $\mathrm{NmE}$ relative to $<\mathrm{NmE}>$ presented in Figure 4 (6.7-10.6 \% in March and $6.0-7.7 \%$ in October) are comparable with that given by Moore et al. [2006].

The primary source of metals existing in the mesosphere and low thermosphere as metallic layers [e.g., $\mathrm{Na}, \mathrm{Fe}, \mathrm{Ca}, \mathrm{Mg}$, and $\mathrm{K}$ ] is ablation of meteoroids in the atmosphere [see, e.g., Kopp, 1997; Ceplecha et al., 1998; Plane et al., 2015, and references therein]. After ablation, metal vapor densities are changed by diffusion and chemical reactions of metals with components of the atmosphere, forming altitude distributions of metal atoms at altitudes of the ionosphere. In addition to the ionization of metal atoms in their hyperthermal collisions with $\mathrm{N}_{2}, \mathrm{O}_{2}$, and $\mathrm{O}$, chemical reactions of these metals with $\mathrm{O}_{2}{ }^{+}$and $\mathrm{NO}^{+}$ionospheric ions produce metal ions at $\mathrm{E}$ - and $\mathrm{D}$-region altitudes of the ionosphere [see, e.g., Pavlov, 2014, and references therein]. A sharp change in the direction of the hydrodynamic velocity of the atmosphere (wind shift) causes changes in number densities of metallic ions, forming a thin long-lived sporadic Eslayer electron number density at middle latitudes,

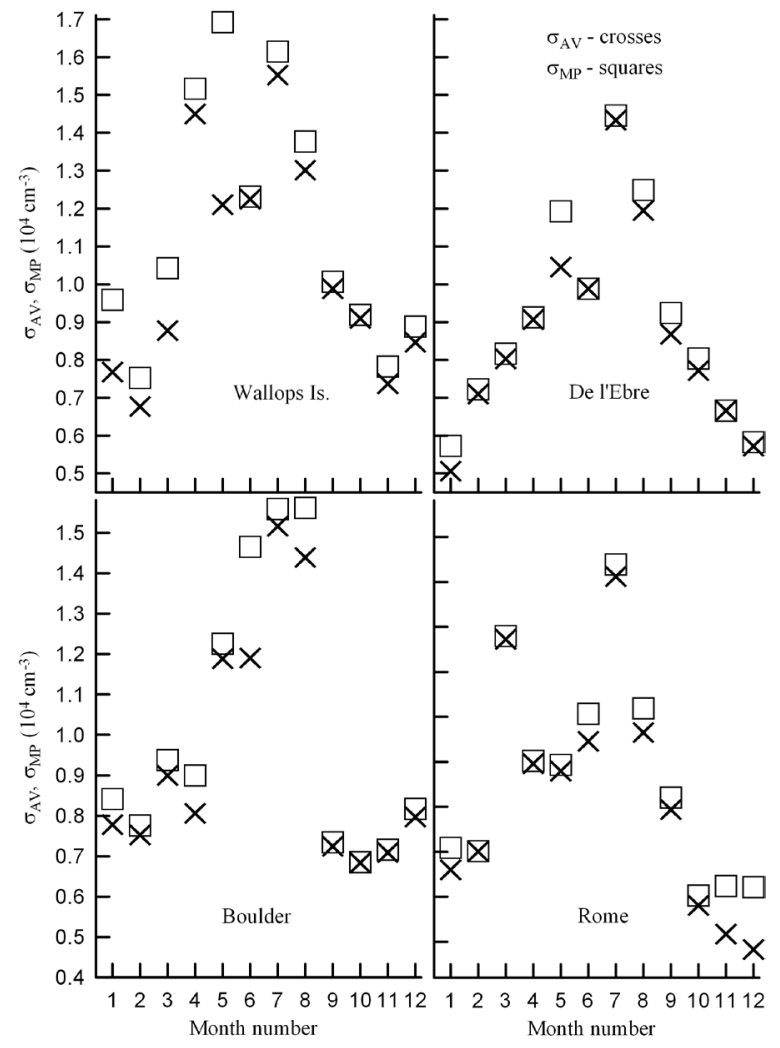

Figure 3. Month-to-month variations of the standard deviations of $\mathrm{NmE}$ from $<\mathrm{NmE}>$ (crosses) and from $\mathrm{NmE}_{\mathrm{MP}}$ (squares) over the Wallops Island (left top panel), Boulder (left bottom panel), de l'Ebre (right top panel), and Rome (right bottom panel) ionosondes.

and the presence of slowly recombining metallic ions is responsible for these Es-layers having the properties of their irregular appearance in time and space [see, e.g., Whitehead, 1989; Haldoupis, 2012, and references therein]. As a result of the ablation of meteoroids, metallic ions exist not only in the Es-layer, but also at all E-region altitudes of the ionosphere above and below this Es-layer, and number densities of metallic ions under consideration are changed in time and in space. Furthermore, a par of metallic ions is transported along magnetic field lines by diffusion and plasma drift, and metallic ions are observed even at F-region altitudes of the ionosphere [e.g., Fesen and Hays, 1982; McNeil et al., 1996; Carter and Forbes, 1999; Collins et al., 2002; and references therein]. Thus, it can be assumed that a part of $\sigma_{\mathrm{AV}}$ and a part of $\mathrm{CV}_{\mathrm{AV}}$ are produced by variations of metallic ion number densities.

The meteoroid influx into the atmosphere consists of showers when the Earth passes through meteoroid streams and sporadic meteoroids that do not belong to any specific meteoroid stream. The showers are divided into the major and minor meteor showers, and basic parameters of major meteor showers (period of activity, maximum date and so- 


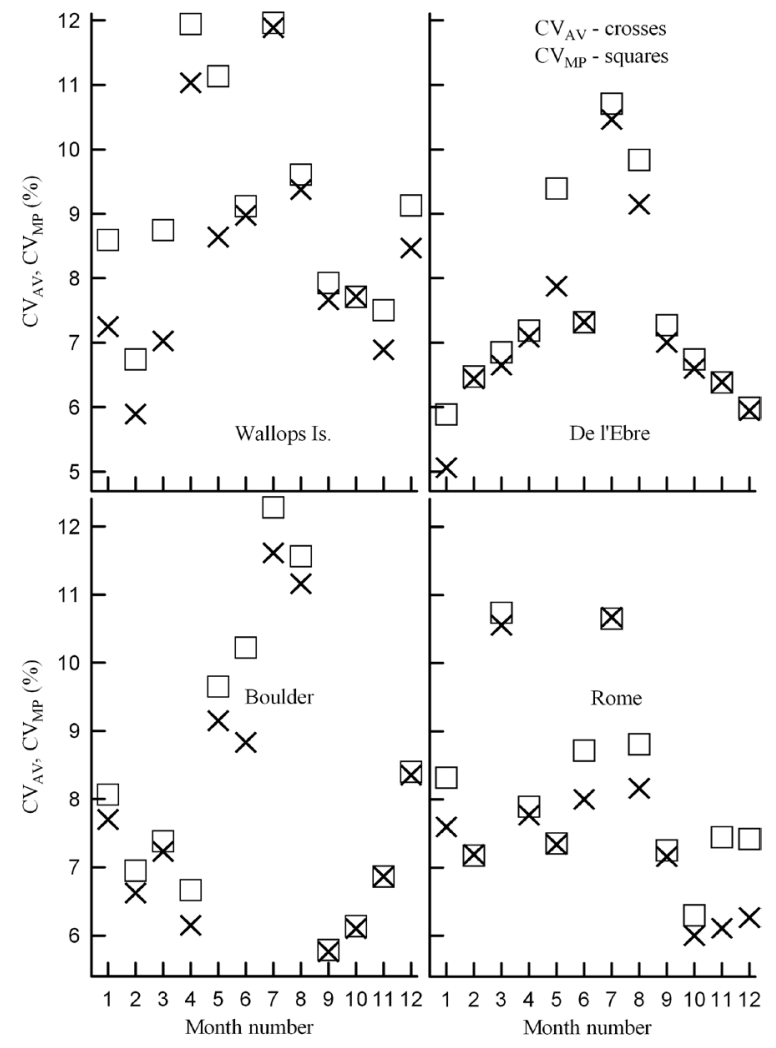

Figure 4. Month-to-month variations of the NmE variation coefficients relative to $<\mathrm{NmE}>$ (crosses) and $\mathrm{NmE}_{\mathrm{MP}}$ (squares) over the Wallops Island (left top panel), Boulder (left bottom panel), de l'Ebre (right top panel), and Rome (right bottom panel) ionosondes.

lar longitude, duration defined as the width of the rate profile at one-quarter of the maximum, radiant, approximate local time of the radiant transit, geocentric velocity and orbital elements) are presented in Table XXII given by Ceplecha et al. [1998]. Some showers have a not regular annual activity, sometimes low, sometimes high, and changes in structures of meteoroid streams result in occasional intense outbursts or enhancements in their activity [Ceplecha et al., 1998]. As a result, month-to-month changes of basic parameters of major meteor showers may have an impact on a part of month-to-month variations of $\sigma_{\mathrm{AV}}$ and $\mathrm{CV}_{\mathrm{AV}}$ shown in Figs. 3 and 4, respectively. In particular, the absence of major meteor showers in February, March, June, and August [see Table XXII given by Ceplecha et al., 1998] should manifest itself in the calculated values of $\sigma_{\mathrm{AV}}$ and $\mathrm{CV}_{\mathrm{AV}}$

It follows from the calculations that the value of $\sigma_{\mathrm{AV}}$ and $\mathrm{CV}_{\mathrm{AV}}$ is changed from one ionosonde to other ionosonde at given month of a year (see Figs. 3 and 4). We believe that these variations of $\sigma_{A V}$ or $\mathrm{CV}_{\mathrm{AV}}$ are caused by changes of $<\mathrm{NmE}>$ from one ionosonde to other ionosonde and by differences in meteoroid populations for locations of the meteoroid influx into the atmosphere at the locations of the ionosondes (i.e., due to irregular distributions of metallic ion clouds in latitude and longitude).

\section{Conclusions}

The long-term statistical analysis of the month-to-month variations of mid-latitude noon $\mathrm{NmE}$ measured by the Wallops Island, Boulder, de l'Ebre, and Rome ionosondes during quiet times in 19572014 revealed notable contributions to the commonly accepted morphology of these variations.

The probability of the occurrence of a geomagnetically quiet $\mathrm{NmE}$ measured by each from 4 mid-latitude ionosondes was calculated at UT close to noon for each month in a year. We found that there are at list two peaks in each dependence of this probability on $\mathrm{NmE}$, and, as a rule, the amplitude of the second-large peak is not much less than amplitude of the greatest peak that determines the most probable NmE. We provide evidence that the calculated month-to-month variations of the most probable $\mathrm{NmE}$ are the less efficient estimation of month-to-month variations of $\mathrm{NmE}$ in comparison with the expectation, $<\mathrm{NmE}>$, of $\mathrm{NmE}$.

The annual maximum of $<\mathrm{NmE}>$ is formed in May (Wallops Island and Rome), June (Boulder), and July (de l'Ebre), and the value of $<\mathrm{NmE}>$ is lowest in its annual value in December. A ratio of the largest to lowest value of $<\mathrm{NmE}>$ that characterizes the maximal month-to-month variability of $\langle\mathrm{NmE}\rangle$ in a year is found to be in the range of 1.40-1.43. We report evidence that there is no the $<\mathrm{NmE}>$ winter anomaly.

The standard deviation of NmE from the mathematically expected $\mathrm{NmE}$ and the coefficient of variations of $\mathrm{NmE}$ relative to $<\mathrm{NmE}>$ calculated in this paper allow to quantitatively describe day-to-day variability of mid-latitude noon $\mathrm{NmE}$ during each month in a year at low solar activity. We found that the standard deviation of $\mathrm{NmE}$ from $<\mathrm{NmE}>$ maximizes in its annual value in July, while the lowest annual value of this statistical parameter of $\mathrm{NmE}$ is found to be in January (de l'Ebre), February (Wallops Island), October (Boulder), and December (Rome). The annual maximum of the coefficient of variations of $\mathrm{NmE}$ relative to $<\mathrm{NmE}>$ occurs in July over the ionosondes under consideration. This statistical parameter of $\mathrm{NmE}$ is minimal in January, February, September, and October over the de l'Ebre, Wallops Island, Boulder, and Rome ionosondes, respectively. The calculated value of this coefficient of variations of $\mathrm{NmE}$ is in the range of $5.1-11.9 \%$. 
Acknowledgments. Hourly critical frequencies foE from the ionospheric sounder stations were provided by the National Geophysical Data Center at Boulder, Colorado. The authors would like to thank reviewers and the Editor for their comments on the paper, which have assisted in improving the final version.

\section{References}

Akasofu, S.I., and S. Chapman (1972). Solar-terrestrial physics, Clarendon Press, Oxford.

Acebal, A.O., and J.J. Sojka (2011), A flare sensitive $3 \mathrm{~h}$ solar flux radio index for space weather applications, Space Weather, 9, S07004, doi:10.1029/2010SW000585.

Banks, P.M., and G. Kockarts (1973). Aeronomy. Part B, Academic Press, New York and London.

Carter, L.N., and J.M. Forbes (1999). Global transport and localized layering of metallic ions in the upper atmosphere, Ann. Geophysicae, 17, 190-209.

Ceplecha, Z., J. Borovička, W.G. Elford, D.O. Revelle, R.L. Hawkes and V.Š.M.

Porubčan (1998). Meteor Phenomena and Bodies, Space Sci. Rev., 84, 327-471.

Collins, S.C., J.M.C. Plane, M.C. Kelley, T.G. Wright, P. Soldán, T.J. Kane, A.J. Gerrard,

B.W. Grime, R.J. Rollason, J.S. Friedman, S.A. Gonzalez, Q. Zhou, M.P. Sulzer and C.A. Tepley (2002). A study of the role of ion-molecule chemistry in the formation of sporadic sodium layers, J. Atmos. Sol. - Terr. Phys., 64, 845-860.

Fesen, C.G., and P.B. Hays (1982). $\mathrm{Mg}^{+}$morphology from visual airglow experiment observations, J. Geophys. Res., 87, 9217-9223.

Haldoupis, C. (2012). Midlatitude Sporadic E. A Typical Paradigm of Atmosphere-Ionosphere Coupling, Space Sci. Rev., 168, 441-461.

Hedin, A.E. (1987). MSIS-86 thermospheric model, J. Geophys. Res., 92, 4649-4662.

Johnson, N.L. and F.C. Leone (1977). Statistics and experimental design in engineering and the physical Sciences, Vol. I., Second edition, John Wiley $\&$ Sons, New York - London - Sydney - Toronto.

Kouris, S.S., and D.N. Fotiadis (2002). Ionospheric variability: a comparative statistical study, Adv. Space Res., 29(6), 977-985.

Kopp, E. (1997). On the abundance of metal ions in the lower ionosphere, J. Geophys. Res., 102, 9667-9674.

Manson, J.E. (1976). The solar extreme ultraviolet between 30 and 205 A on November 9, 1971, compared with previous measurements in this spectral region, J. Geophys. Res., 81, 1629-1635.

McNeil, W.J., R.A. Dressler and E. Murad (2001). Impact of a major meteor storm on Earth's ionosphere: a modeling study, J. Geophys. Res., 106, 10447-10466.

Moore, L., M. Mendillo, C. Martinis and S. Bailey (2006). Day-to-day variability of the E layer, J. Geophys. Res., 111, A06307, doi:10.1029/2005JA011448.

Nicolls, M.J., F.S. Rodrigues and G.S. Bust (2012). Global observations of E region plasma density morphology and variability, J. Geophys. Res., 117, A01305, doi:10.1029/2011JA017069.

Pavlov, A.V. (2012). Ion Chemistry of the Ionosphere at the E- and F-region Altitudes: A Review, Surveys in Geophysics, 33, 1133-1172.

Pavlov, A.V., and N. M. Pavlova (2005). Causes of the mid-latitude NmF2 winter anomaly, J. Atmos. Sol. Terr. Phys., 67, 862-877.

Pavlov A.V., and N.M. Pavlova (2009) Anomalous variations of $\mathrm{NmF} 2$ over the Argentine Islands: a statistical study, Ann. Geophysicae, 27, 1363-1375.

Pavlov, A.V., N. M. Pavlova, and S. F. Makarenko (2010). A statistical study of the mid-latitude NmF2 winter anomaly, Adv. Space Res., 45(3), 374-385.

Pavlov, A.V., and N.M. Pavlova (2013). Comparison of $\mathrm{NmE}$ measured by the Boulder ionosonde with model predictions near the spring equinox, J. Atmosph. Solar-Terr. Phys., 102, 39-47.

Pavlov, A.V., and N.M. Pavlova (2014). Influence of the equinoctial asymmetry on the semi-annual anomaly in NmF2 near noon in the northern geographic hemisphere: a statistical study, Adv. Space Res., 53(4), 619-634.

Pavlov, A.V., and N.M. Pavlova (2015). Comparison of Electron Concentrations in the Ionospheric E-Layer Maximum in Spring Conditions Obtained by Calculations and Moscow Ionosonde Measurements, Geomagnetism and Aeronomy, 55, 235245, doi:10.1134/S0016793215040118.

Picone, J.M., A.E. Hedin, D.P. Drob, and A.C. Aikin (2002). NRLMSISE-00 empirical model of the atmosphere: statistical comparisons and scientific issues, J. Geophys. Res., 107, 1468, doi:10.1029/2002JA009430.

Piggott, W. R. and K. Rawer (Eds.) (1978). URSI handbook of ionogram interpretation and reduction, National Oceanic and Atmospheric Administration, CO, Boulder.

Plane, J.M.C., W. Feng and E.C.M. Dawkins (2015). The Mesosphere and Metals: Chemistry and Changes, Chemical Reviews, 115, 4497-4541.

Richards, P.G., J.A. Fennelly and D.G. Torr (1994). EUVAC: A solar EUV flux model for aeronomical Calculations, J. Geophys. Res., 99, 8981-8992.

Schunk, R.W., and A.F. Nagy (2009). Ionospheres. 
Physics, plasma physics, and chemistry. University Press, Cambridge.

Sojka, J.J., J.B. Jensen, M. David, R.W. Schunk, T. Woods, F. Eparvier, M.P. Sulzer,

S.A. Gonzalez, and J.V. Eccles (2014) Ionospheric model-observation comparisons: E layer at Arecibo Incorporation of SDO-EVE solar irradiances, J. Geophys. Res., 119, 3844-3856.

Solomon, S.C. (2006). Numerical models of the E-region ionosphere, Adv. Space Res., 37 (5),1031-1037.

Whitehead, J.D. (1989). Recent work on mid-latitude and equatorial sporadic-E, J. Atmos. Terr. Phys., 51, $401-424$.

${ }^{\star}$ Corresponding author: Anatoli Pavlov, Pushkov Institute of Terrestrial Magnetism, Ionosphere and Radio Wave Propagation (IZMIRAN), Russia Academy of Science,142190, Troitsk, Moscow, Russia; e-mail: pavlov@izmiran.ru 